\title{
Experimental stand for investigation of fluid flow in heat exchangers with cross-flow arrangement
}

\author{
Stanisław Łopata ${ }^{1, *}$, Paweł Ocłoń ${ }^{1}$, and Marzena Nowak-Ocłoń ${ }^{1}$ \\ ${ }^{1}$ Cracow University of Technology, al. Jana Pawła II 37, 31864 Kraków, Poland
}

\begin{abstract}
The operation analysis of high-performance heat exchanger with tubes elliptical indicated that the heat exchangers can be subject to damage. The reason for this is probably improper distribution of working fluid in tubular space of heat exchanger. Therefore, a part of the tubes may be improperly cooled and subject to compressible stresses. The paper presents an experimental stand allowing to confirm the given assumption. The experimental investigation enables to examine the mass flow rate in heat exchanger tubes. Also, it is possible to assess the impact of the construction of inlet, intermediate and outlet chambers on the flow distribution within the heat exchanger tubes.
\end{abstract}

\section{Introduction}

The operation of the high-performance heat exchanger with finned elliptical tubes in cross-flow working fluid arrangement (e.g. flue gas-water), indicates a possibility of failure. This situation occurs mainly in the case when a large difference between the working fluid temperatures exists. The failure can be seen as a certain deformation of tubes in the form of buckling, or as a tube rupture. Examples of the construction of heat exchangers which are mentioned here, often refer to highperformance heat exchangers are shown in Fig. 1 [1, 2]. Figure 2 shows a structure (the basic elements) and the principle of operation.
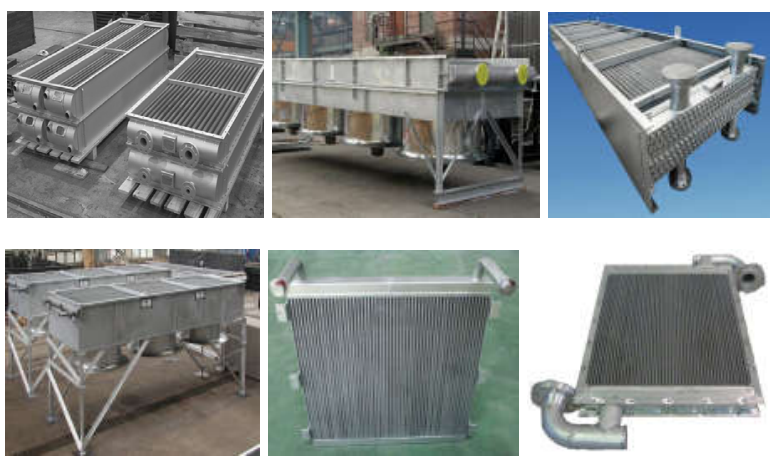

Fig. 1. Examples of construction of high-performance heat exchangers heater/cooler

Due to the external fins, the efficiency of fin-andtube heat exchangers in high. The fins are densely assembled on heat exchanger tubes. Thus the heat transfer area is large. The advantages of the heat exchanger, together with the high efficiency, are relatively small size (compactness of construction) at a relatively high power (e.g. in comparison with conventional shell-and-tube structures with the same capacity, but with smooth tubes).

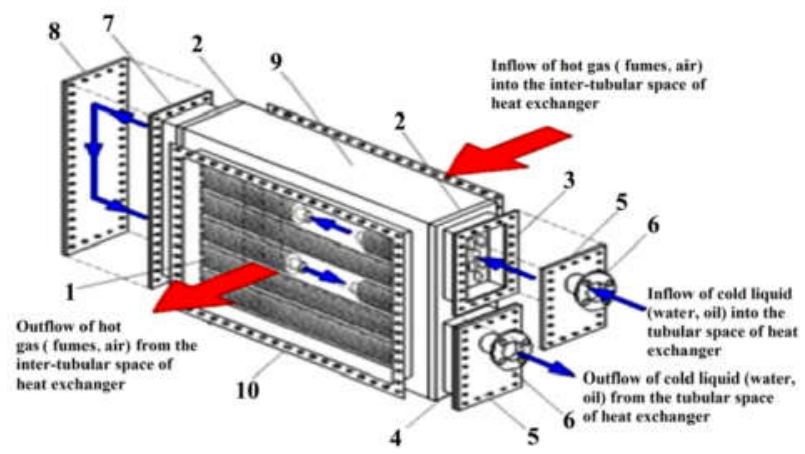

Fig. 2. High-performance heat exchanger with finned tubes: 1 - finned elliptical tubes, 2 - sieve plate, 3 - inlet chamber, 4 - outlet chamber, 5, 8 - chamber cover, 6 -inlet/outlet nozzle, 7 - intermediate chamber, 9 - shell, 10 - flange connecting heat exchanger with channel (e.g.. air, flue-gas flow)

They are widely used in different applications, such as in heavy industry, power generation, chemical processing, as well as in the automotive industry or refrigeration systems. Also, high-performance heat exchangers can be found in heat recovery systems (e.g. to cool down the exhaust gas) in air-conditioning units, among others.

\section{Heat exchanger with finned elliptical tubes - exploitation/construction problems}

The exploitation of equipment is accompanied by failures and damage [3-7], and in the field of heat exchangers, there are no exception. This statement is

\footnotetext{
* Corresponding author: lopata@mech.pk.edu.pl
} 
evident, but it is often problematic to find a reason of the failure, which usually requires a thorough analysis of many factors including the flow and heat transfer, as well as the distributions of stress and deformation of the structure [8-12]. Moreover, these issues are gaining importance in cases of repeated operational problems, especially damage [7, 12]. Examples of heat exchanger failures (with the cross-flow arrangement of flue gas and water), are shown in Fig. 3. By the local inspection, the nature of the damage was found. The buckling of several tubes (in both heat exchanger passes) and fractured tube nearby the sieve plate, shows that the compressible stresses were the reason of failure.
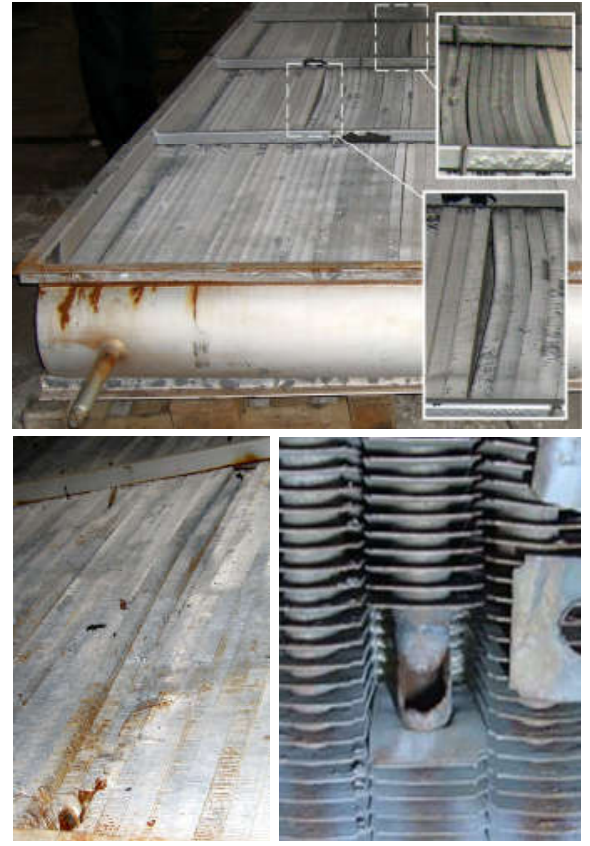

Fig. 3. Buckling and fracture of heat exchanger tubes

Figure 3 presents damages on a heat exchanger; that is structurally similar to the one shown in Fig. 2, but vertically disposed and had a profiled chamber: inlet, intermediate, and outlet. The chambers are formed from the large pipes Fig. 4). The heat exchanger operated in one of the heat recovery units in Poland. The problems already appeared after three months from the date of heat exchanger launch. It should be noted that a new device (which was inserted in place of the previous) also suffered a failure, after eight months of operation and both the location of damage, as well as their nature was similar [7, 11].

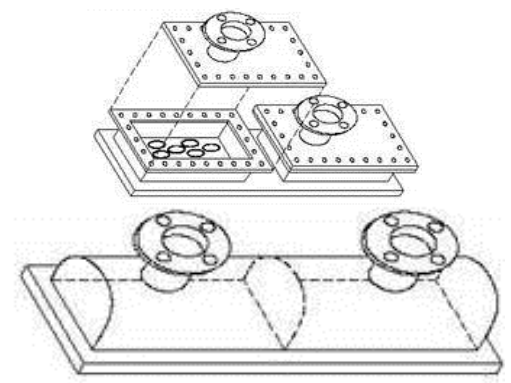

Fig. 4. The shape of heat exchanger headers used in cross-flow heat exchangers
The reason of tube damage can be improper operational conditions, such as raw water (with limescale) formed as a result of the internal surfaces impurities whose presence contributes to a significant increase in temperature and stresses, even exceeding the limit value [12-15]. Also, the small volume of the heat exchanger headers hampers the proper flow distribution to the tubes located in both passes, what has been confirmed by numerical modeling [9-12]. Fig. 5 shows the scheme of the analyzed heat exchanger, and in Fig. 6 the value of the mass flow rate in tubes of both passes (for the first row of tubes, i.e. from the flue gas flow) are depicted. The CFD simulations $[12,16]$ were performed in ANSYS CFX software for various numbers of finite elements and indicated an abnormal flow distribution in heat exchanger tubes.

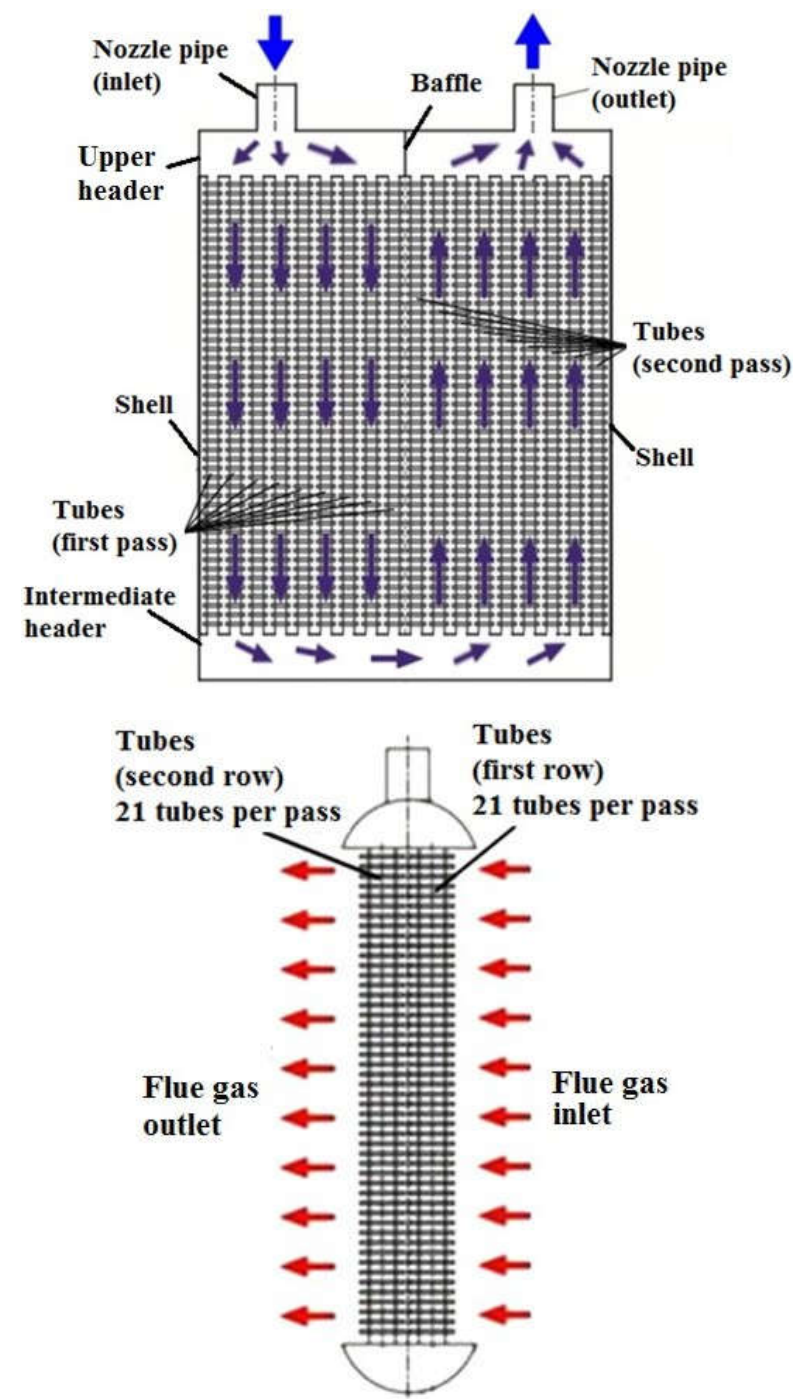

Fig. 5. Scheme of the two-pass cross-flow heat exchanger

The considerable variations in the water flow rate result in increased temperature of water in heat exchanger tubes (Fig. 7). Figure 7 reveals that the water temperature differences are up to $45{ }^{\circ} \mathrm{C}$ and the saturation temperature is reached in tubes no 10 (first pass of the heat exchanger) and 22 (second pass of the heat exchanger). 


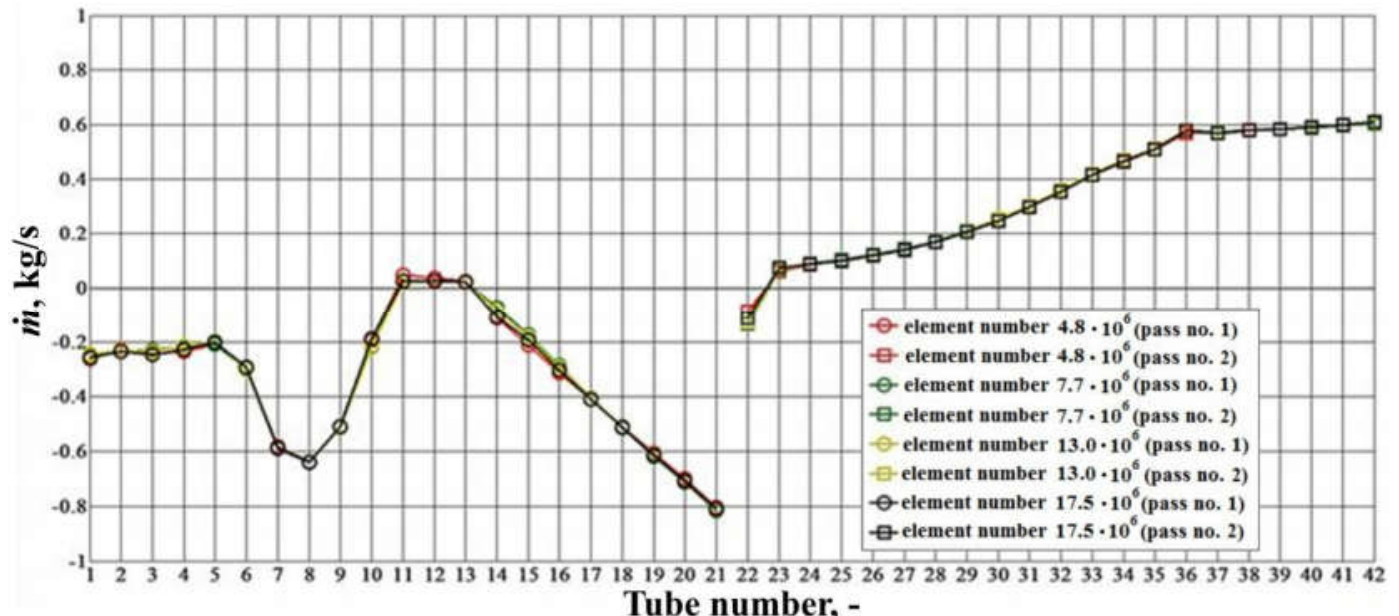

Fig. 6. Water mass flow rate in elliptical tubes of the heat exchanger of the first pass - tubes no. $1 \div 21$, of the second pass - tubes no. $22 \div 42$ (the legend shows number of finite element used)

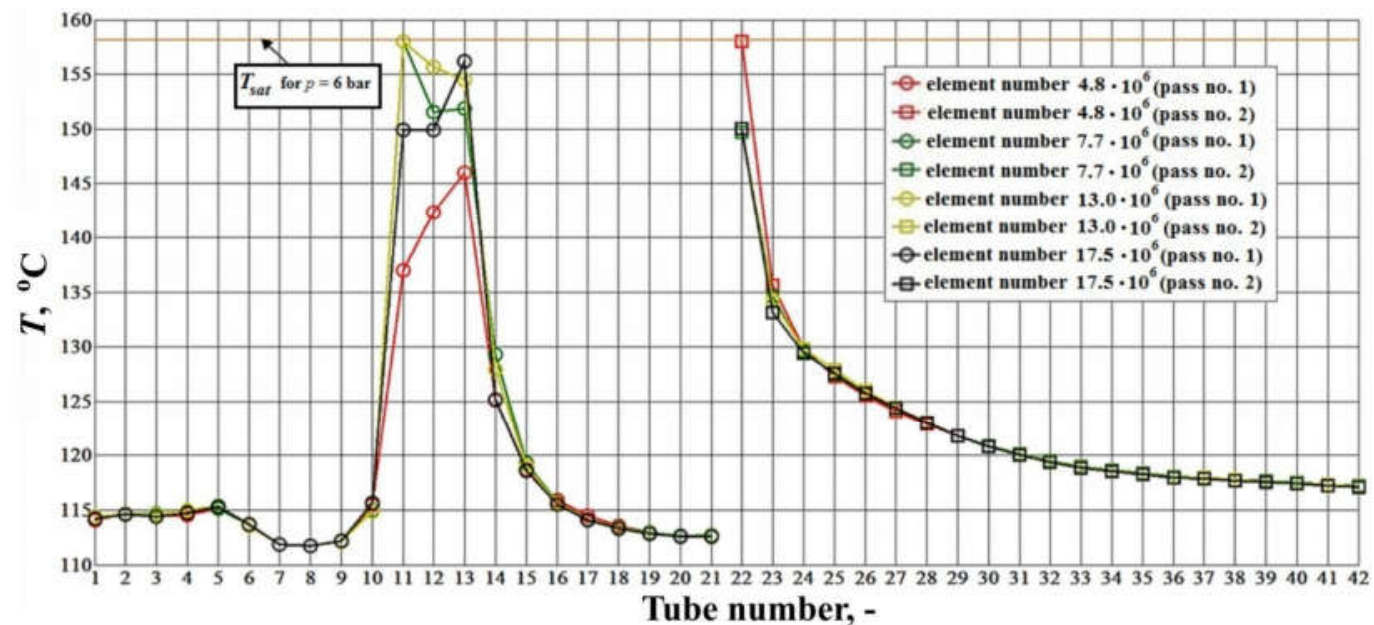

Fig. 7. Average water temperature in elliptical tubes of the heat exchanger of the first pass - tubes no. $1 \div 21$, of the second pass tubes no. $22 \div 42$ (the legend shows number of finite element used)

The analysis of Fig. 6 reveals that the flow of coolant (in this case water) in the heat exchanger tubes is very diverse, with the largest value is approx. $0.8 \mathrm{~kg} / \mathrm{s}$ (for tube 21) and the smallest, approx. $0,02 \mathrm{~kg} / \mathrm{s}$ (tube 11, 12 and 13). In both cases, the differences exist in the tubes of the first pass. In the second pass, the highest value of flow rate is approx. $0.6 \mathrm{~kg} / \mathrm{s}$, and applies to tubes $36 \div 42$, and the lowest, approx. $0.1 \mathrm{~kg} / \mathrm{s}$, to the tube 22. From Fig. 6 one can observe the different sign of mass flow rate in tubes no. 11 to 13 of first pass and tube no 22 of the second pass (compared to adjacent tubes). This situation indicated the reverse flow of water. This situation leads to a significant increase in water temperature (may cause the flow boiling $[17,18]$ in the case of low flow rate) since the path of the flow is repeated several times. Figure 6 shows that the water flow rate in the pipes is very low. The flow rate is one of the most important factors affecting the intensity of the heat transfer process. Hence, the conditions of heat removal in the individual pipes are different. In this regard very unfavorable conditions apply to the tubes with low flow rates of water, especially characterized by backflow. In this case, one can expect high thermal stresses, which can contribute significantly to the heat exchanger failure. It should be noted that the previously described damage underwent the tubes corresponding to the unfavorable conditions of the heat exchanger (tubes no. 11-13 in the first pass, tube no. 22 in the second pass). The observed improper flow distribution in crossflow heat exchanger (Fig. 6) leads to the significant temperature differences in the tubes located in both passes. As it can be seen in Fig. 7, in the tubes with the reverse-flow, the water temperature is significantly higher compared to other tubes. Maximum reach approx. $158^{\circ} \mathrm{C}$ (this corresponds to a saturation temperature at a pressure of 6 bars, for which calculations were performed [12]) and the lowest is approx. $112^{\circ} \mathrm{C}$. Those differences significantly affect the temperature of the tube wall and result in the thermal stresses. Due to a considerable stiffness of sieve plates, the tubes with the lower temperature exhibit tensile stresses, while those with the higher the compressible stresses $[10,11]$.

The flow boiling and local evaporation of water [18] accelerate the process of limescale formation (in the case of raw or improperly treated water). In such a situation, the limescale will cause a further increase in the

* Corresponding author: lopata@mech.pk.edu.pl 
temperature of the tube wall and may result in even higher thermal stresses. This disadvantageous effect (lower heat transfer rate) will also be caused by contaminants transported through a heating medium (e.g., the exhaust gas) and accumulated on the outer surface of tubes.

The possible solution to improve the working conditions of the analyzed heat exchanger is the change the shape of headers. The new solution (the patent procedure is in progress) is shown in Fig. 8.

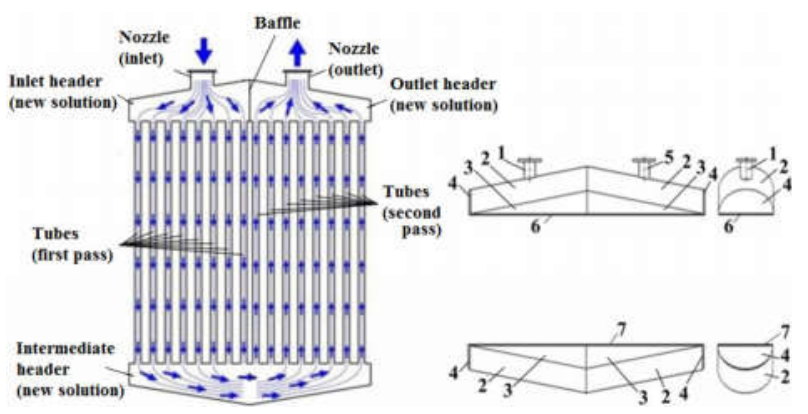

Fig. 8. A scheme of the two-row/two-pass high performance heat exchanger (of water/flue gas type) with the new shape of headers: 1 -inlet nozzle, 2, 3-header combined from the tube sector (2) and two wedges (3), 4 - bottom, 5 - outlet nozzle, 6 - sieve plate (connected with outlet and inlet headers separated by the baffle), 7 - sieve plate (connected with intermediate header)

Because a new inlet, intermediate and outlet headers with increased flow space are proposed, a uniform flow distribution to heat exchanger tubes is expected. However, to confirm the expectation, the extensive experimental investigations are needed.

\section{Experimental stand}

Figure 9 presents a schematic and general view of the test stand (for investigation of flow distribution in the heat exchanger with elliptical tubes). Various interchangeable inlet and outlet chambers are depicted in Figs. 10 and 11.
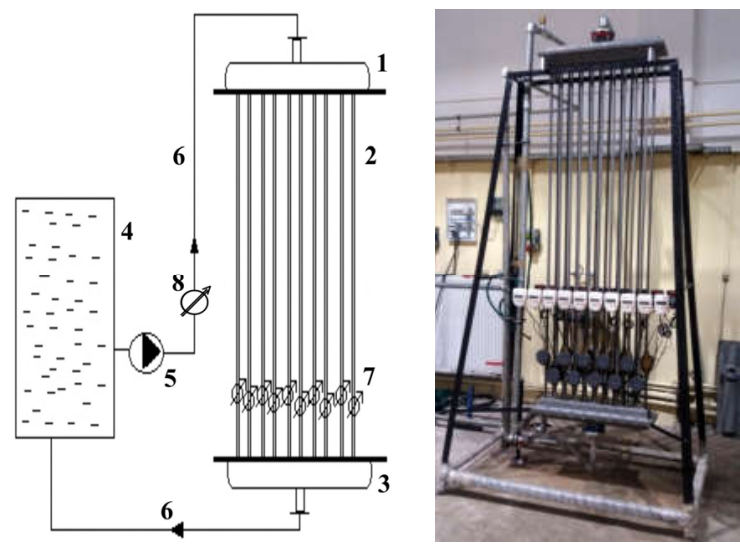

Fig. 9. Schematic of the stand for investigation of flow distribution in heat exchanger with elliptical tubes: 1 - inlet header with nozzle pipe, 2 - tubular space of heat exchanger (elliptical tubes), 3 - outlet header with nozzle pipe, 4 - water tank, 5 - feed pump, 6 - connections, 7 -flowmeters located in each tube, 8 - flow meter of total flow rate of working fluid
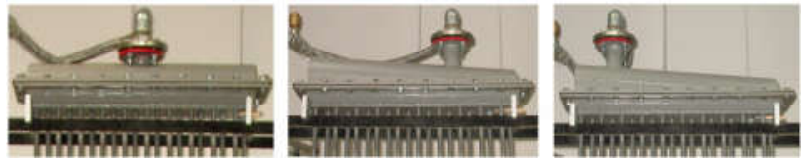

Fig. 10. Examples of inlet headers with various location of nozzle pipe
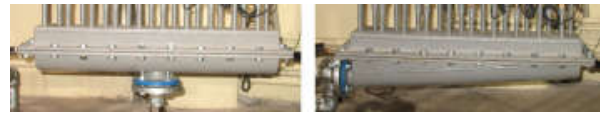

Fig. 11. Examples of outlet headers with various location of nozzle pipe

The stand presented in Figs. 10 and 11, enables to install two different shapes of the heat exchanger header. The solution used by heat exchanger manufacturers and a proposed shape of the header. Also, for each solution (the new and existing) it is possible to test various location of inlet/outlet nozzle pipes. Therefore, the investigation of various flow configuration is possible.

A view of sieve plate and its flange connection with heat exchanger header is shown in Fig. 12, the assembly of outlet header to the flange with sieve plate is presented in Fig. 13.

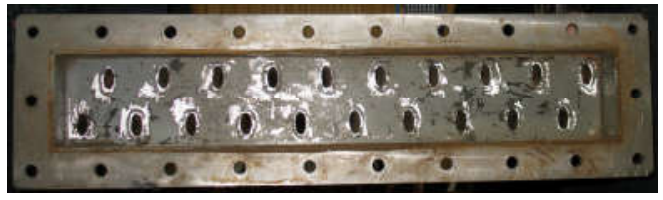

Fig. 12. A view of sieve plate and its connection with heat exchanger header

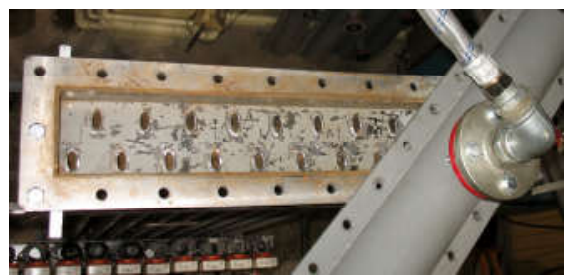

Fig. 13. The assembly of outlet header to sieve plate

The Sontex Superstatic 749 flowmeters are used for the measurement of the instantaneous flow rate in individual heat exchanger tubes [19]. The another flowmeter is installed before the heat exchanger to control the total flow rate and the indications of the flowmeters located within the tubes.

\section{Closing remarks}

The reason for a failure of the high-performance heat exchanger used for heat recovery from exhaust gasses may be the irregular distribution of working fluid (e.g. water) flowing in the tubular space. It can be related to the not appropriate design of the heat exchanger headers: the inlet, the intermediate and the outlet. As a result, in the tubes of the heat exchanger, flow rate and temperature of the medium may vary considerably. Numerical calculations confirm this fact and allow to determine the zones of heat exchanger tube, where the 
flow is significantly lower than in other ones. The low flow rate of coolant causes the ineffective heat reception and leads to the increased tube wall temperature. Consequently, the excessive thermal stresses occur and may result in the heat exchanger failure.

The new construction of the heat exchanger headers were proposed. Changing the design of the headers may improve the coolant flow distribution in heat exchangers tubular space. Both the coolant flow rate and temperature are more uniformly distributed within the tubes of heat exchanger pass.

The experimental verification of the proposed design of heat exchanger header shall be performed. Therefore, the experimental stand to the analysis of flow distribution in the heat exchanger with elliptical tubes was made. The stand allows measuring the working fluid flow rates separately within each tube of the heat exchanger. The measurements can be performed for various types of heat exchanger headers, and location of inlet and outlet nozzle pipe. In future, the authors plan to validate the CFD simulation results, through the investigation performed at the newly created stand.

\section{References}

1. GEA company website (http://www.geatc.com.pl/High-performance-heat-exchange)

2. Websites of fin-and-tube heat exchangers producers (http://gzgele.en.made-in-china.com/productimage/; http://www.made-in-china.com/showroom/; http://www.weiku.com/products-image/)

3. N.V. Challenger, R. Phaal, S.J. Garwood, Fracture mechanics assessment of industrial pressure vessel failures, Int. J. of Pressure Vessels and Piping, 61 (2-3), pp. 433-456 (1995)

4. S.H. Dai, Failure analysis and life prediction of a set of extra high pressure heat exchangers containing defects, Int. J. of Pressure Vessels and Piping, 70 (3), pp. 197-200 (1997)

5. M.S. Liu, Q.W. Dong, D.B. Wang, X. Ling, Numerical simulation of thermal stress in tube-sheet of heat transfer equipment, Int. J. of Pressure Vessels and Piping, 76 (10), pp. 671-675 (1999)

6. D. Butrymowicz, M. Trela, Effects of fouling and inert gases on performance of recuperative feedwater heaters, Archives of Thermodynamics, No. 12, 23 (2001)

7. S. Łopata, W. Krzanowski, S. Pytel, P. Ocłoń, The heat exchanger of flue gas/water type failure analysis, and the possibility of design changes for the improvement of device operation (in polish, unpublished expertise), Cracow University of Technology, PK M-5/429/2009 (2009)

8. S. Łopata, P. Ocłon, Investigation of the flow conditions in a high-performance heat exchanger, Archives of Thermodynamics, 31, No. 3, pp. 37-53 (2010)

9. P. Ocłoń, S. Łopata, Modeling of the flow distribution inside the collectors of the highperformance heat exchanger, Technical Transactions, Mechanics, Cracow University of
Technology, z. 4-M/2011/B, Issue 7, Year 108, pp. 391-400 (2011)

10. S. Łopata, P. Ocłoń, Analysis of operating conditions for high-performance heat exchanger with the finned elliptical tube, Rynek Energii, 102, No 5, pp. 112-124 (2012)

11. S. Łopata, P. Ocłoń, Modelling and Optimizing Operating Conditions of Heat Exchanger with Finned Elliptical Tubes. Edited by L. H. Juarez, Fluid Dynamics, Computational Modeling and Applications, Part 3, chapter 14, InTech, ISBN: 978953-51-0052-2, pp. 327 - 356, Croatia (2012)

12. P. Ocłoń, Coupled flow-thermal and structural analysis of operating conditions for heat exchanger with finned elliptical tubes, $\mathrm{PhD}$ Thesis (in polish), Kraków (2013)

13. S. Łopata, P. Ocłon, The stress state analysis of the high performance heat exchanger, Technical Transactions, Mechanics, Cracow University of Technology, z. 4-M/2011/B, Issue 7, Year 108, pp. 359-368 (2011)

14. P. Ocłoń, S. Łopata, M. Nowak, A.C. Benim, Numerical study on the effect of inner tube fouling on the thermal performance of high-temperature finand-tube heat exchanger, Progress in CFD, 15, Issue 5, pp. 290-306 (2014)

15. S. Łopata, P. Ocłoń, Numerical study of the effect of fouling on local heat transfer conditions in a hightemperature fin-and-tube heat exchanger, Energy, 92, 1, pp. 100-116 (2015)

16. D. Taler, P. Ocłoń, Thermal contact resistance in plate fin-and-tube heat exchangers, determined by experimental data and CFD simulations, Int. J. of Thermal Sciences, 84, pp. 309-322 (2014)

17. P. Ocłoń, S. Łopata, M. Nowak, A novel 1D/2D model for simulating conjugate heat transfer applied to flow boiling in tubes with external fins, Heat and Mass Transfer/Waerme- und Stoffuebertragung, 51 (4), pp. 553-566 (2015)

18. P. Ocłoń, M. Nowak, S. Łopata, Simplified numerical study of evaporation processes inside vertical tubes, J. of Thermal Science, 23 (2), pp. 177-186 (2014)

19. P. Ocłoń, S. Łopata, K. Chłosta, Experimental and Numerical Investigation of Flow Distribution within the Heat Exchanger with Elliptical Tubes, Procedia Engineering, 157, pp. 428-435 (2016) 